\title{
RECONTEXTUALIZAÇÃO DA POLÍTICA CURRICULAR PARA A EDUCAÇÃO DAS RELAÇÕES ÉTNICO-RACIAIS
}

\author{
Etelvina de Queiroz Santos (UESB)* \\ Núbia Regina Moreira (UESB)**
}

\section{RESUMO}

Este artigo apresenta os resultados de uma pesquisa que buscou compreender como se recontextualizam as políticas curriculares para a educação das relações étnico-raciais para o Ensino Médio, Técnico e Tecnológico do IF Baiano campus Guanambi. Tem como principal referencial as contribuições de Basil Bernstein com a teoria da recontextualização, os estudos de Ball e Bowe sobre ciclo de políticas e, também, os estudos no campo do currículo e das relações étnicoraciais. A investigação questionou como a educação para as relações étnicoraciais é recontextualizada na prática das professoras de Arte, Língua Portuguesa e História da referida instituição de ensino. Os dados foram construídos por meio da análise de documentos oficiais e entrevistas semiestruturadas. Ao longo da pesquisa, percebeu-se como se efetiva, no cotidiano escolar, por meio da prática pedagógica, o processo de recontextualização das propostas curriculares para educação das relações étnico-raciais.

Palavras-chave: Ciclo de políticas. Relações étnico-raciais. Prática pedagógica. Recontextualização.

\section{ABSTRACT}

\section{RECONTEXTUALIZATION OF THE CURRICULAR POLICY FOR THE EDUCATION OF ETHNIC-RACIAL RELATIONS}

This article present the results of a research that sought to understand how the curricular policies are recontextualized for the education of the ethnic-racial relations for the High School, Technical and Technological of the IF Baiano campus Guanambi. It has as references the contributions of Basil Bernstein's with the recontextualization theory, Ball and Bowe's studies on the policy cycle, as well as studies in curriculum and ethnic-racial relations. The research has questioned how is education for ethnic-racial relations recontextualized in the practice of the teachers of Art, Portuguese Language and History of the

* Mestre em Educação pela Universidade Estadual do Sudoeste da Bahia (UESB). Professora da Educação Básica da Rede Estadual de Ensino no Município de Candiba (BA). E-mail: vik714@hotmail.com

** Doutora em Sociologia pela Universidade de Brasília (UnB). Docente do Mestrado em Educação da Universidade Estadual do Sudoeste da Bahia (UESB). Membro da Associação Brasileira de Currículo (ABdC), da Associação Nacional de Pós-Graduação e Pesquisa em Educação (ANPEd) e da Associação Brasileira de Pesquisadores Negros (ABPN). E-mail: nrmoreira2@yahoo. com.br 
said institution of teaching? The data were constructed through the analysis of official documents and semi-structured interviews. Throughout the research, it was perceived how to realize, in the school routine, through the pedagogical practice, the recontextualization process of the curricular proposals for the education of ethnic-racial relations.

Keywords: Policy cycle. Ethnic-racial relations. Pedagogical practice.

Recontextualization.

\section{RESUMEN}

\section{RECONTEXTUALIZACIÓN DE LA POLÍTICA CURRICULAR PARA LA EDUCACIÓN DE LAS RELACIONES ÉTNICO-RACIALES}

Este artículo presenta los resultados de una investigación que buscó comprender cómo se recontextualizan las políticas curriculares para la educación de las relaciones étnico-raciales para la Enseñanza Media, Técnico y Tecnológico del IF Baiano campus Guanambi. Tiene como principal referencial las contribuciones de Basil Bernstein con la teoría de la recontextualización, los estudios de Ball y Bowe sobre ciclo de políticas y, también, los estudios en el campo del currículo y de las relaciones étnico-raciales. La investigación cuestionó cómo la educación para las relaciones étnico-raciales es recontextualizada en la práctica de los profesores de Arte, Lengua Portuguesa y História de la dicha institución de enseñanza. Los datos fueron construidos a través del análisis de documentos oficiales y entrevistas semiestructuradas. A lo largo de la investigación, se percibió cómo se efectúa, en el cotidiano escolar, por medio de la práctica pedagógica, el proceso de recontextualización de las propuestas curriculares para la educación de las relacines étnico-raciales.

Palabras clave: Ciclo de políticas. Relaciones étnico-raciales. Práctica pedagógica. Recontextualización.

\section{Introdução}

0 presente trabalho constitui-se um recorte da pesquisa de mestrado Práticas das Políticas Curriculares sobre as Relações Étnico-Raciais no Instituto Federal Baiano - Campus Guanambi (SANTOS, 2018) e apresenta uma discussão a respeito de como se recontextualizam as políticas curriculares para educação das relações étnico-raciais para o Ensino Médio, Técnico e Tecnológico do IF Baiano campus Guanambi, do contexto da influência ao contexto da prática. ${ }^{1}$

10 presente texto surge a partir da pesquisa intitulada "Práticas das Políticas Curriculares sobre as Relações Raciais no Instituto Federal Baiano - campus Guanambi". Os procedimentos éticos durante a realização do estudo se basearam na Resolução no 196/96 do Conselho Nacional de Saúde, respeitando os participantes do processo inves-
Neste estudo, tomamos como objeto de pesquisa manifestação das políticas curriculares para as relações étnico-raciais nas práticas pedagógicas. Para tanto, nos orientamos pelos referenciais do conceito de recontextualização de Basil Bernstein (1996), pelos estudos de Ball e Bowe (1992) e Ball $(1997,1998)$, e nos apropriamos dos conhecimentos produzidos sobre o ciclo de políticas e, também, os estudos no campo do currículo e das relações étnico-raciais.

\footnotetext{
tigativo em sua dignidade e autonomia, reconhecendo sua vulnerabilidade, assegurando sua vontade sob a forma de manifestação expressa, livre e esclarecida, de contribuir e permanecer ou não na pesquisa. Esta foi submetida à apreciação ética e está registrada na Plataforma Brasil sob o no CAAE 65143517.4.0000.8089.
} 
O conceito de recontextualização de Bernstein (1996) defende que o discurso pedagógico não é um discurso em si, mas um princípio de recontextualização que se apropria de outros discursos e os realocam de acordo sua própria lógica de ordenamento. Bernstein (1996) identifica a presença de dois campos recontextualizadores pedagógicos: o oficial e o não oficial. Nesta pesquisa, acessamos o campo oficial por meio dos documentos: Lei no 10.639/03 (BRASIL, 2003), Diretrizes Curriculares Nacionais para a Educação das Relações Étnico-Racial e para o Ensino de História e Cultura Afro-Brasileira e Africana (BRASIL, 2004a), Parecer CNE/ CP no 3 (BRASIL, 2004b), Plano de Desenvolvimento Institucional 2015-2019 do Instituto Federal Baiano (INSTITUTO FEDERAL BAIANO, 2014) e Projeto Político Pedagógico da referida escola (INSTITUTO FEDERAL BAIANO, 2016), com o objetivo de apreendermos como o discurso pedagógico para a educação das relações étnico-raciais é produzido nesses documentos. No campo não oficial (práticas, conteúdos), buscamos perceber "o que" está sendo dito, "como" está sendo dito, a forma de transmissão e recontextualização dos documentos oficiais, por meio de entrevista com professores de Arte, Língua Portuguesa e História. ${ }^{2}$

Além disso, ao compreendermos como as políticas são pensadas e colocadas em prática, utilizamos como terreno heurístico a abordagem do ciclo de políticas de Ball (1994a). Segundo este autor, os textos políticos são o resultado de uma série de negociações, de múltiplas influências e intenções. Em seu processo de construção, algumas vozes são legitimadas e ouvidas, e outras, obviamente, ficam de fora, mesmo que circunstancialmente. Segundo Ball (1994a), o contexto de produção de textos é a arena de elaboração da política em que sujeitos disputam por legitimar visões

2 A escolha das professoras de Arte, Língua Portuguesa e História se deu para atender às determinações da Lei $\mathrm{n}^{\mathbf{0}}$ 10.639 (BRASIL, 2003), modificada pela Lei no 11.645 (BRASIL, 2008), que estabelece que os conteúdos referentes à História e Cultura Afro-Brasileira serão ministrados no âmbito de todo o currículo escolar, em especial nas áreas de Educação Artística, Língua Portuguesa e História. particulares de currículo nos documentos. Este contexto foi acessado por meio de análise documental e confrontado com os relatos das professoras entrevistadas. Destarte, foi possível perceber, ao longo do desenvolvimento da pesquisa, como se efetiva, no cotidiano escolar, por meio da prática pedagógica das professoras, o processo de recontextualização das propostas curriculares para educação das relações étnico-raciais.

\section{Da recontextualização ao ciclo de política: lendo as políticas das relações étnico-raciais}

Nesta seção realizamos uma leitura de como as políticas curriculares para as relações étnico-raciais são desenvolvidas, da recontextualização ao ciclo de políticas. Para esta pesquisa, interessam-nos, especificamente, as formulações referentes ao processo de recontextualização pedagógica dos discursos produzidos no contexto escolar. Bernstein (1996, p. 234) ressalta que "[...] a comunicação pedagógica é o condutor de relações de classe; o condutor de relações de gênero; o condutor de relações religiosas, de relações regionais". Podemos inferir que seja, também, condutor das relações étnico-raciais.

O discurso pedagógico é, pois, um princípio que tira (desloca) um discurso de sua prática e contexto substantivos e recoloca aquele discurso de acordo com seu próprio princípio de focalização e reordenamento seletivos. Nesse processo de deslocação e recolocação do discurso original, a base social de sua prática é eliminada. Nesse processo de deslocação e recolocação, o discurso original passa por uma transformação: de uma prática real para uma prática virtual ou imaginária. [...] Trata-se de um princípio recontextualizador que, seletivamente, apropria, reloca, refocaliza e relaciona outros discursos, para constituir sua própria ordem e seus próprios ordenamentos. (BERNSTEIN, 1996, p. 259).

Nessa teoria, o discurso é um poderoso instrumento capaz de deslocar e realocar o texto original. 0 sujeito da ação educativa tem 
o poder de utilizar dos conhecimentos prévios para interpretar e recontextualizar o discurso formulado originalmente. Assim, os discursos produzidos pelos movimentos negros ao longo dos séculos possibilitaram muitas reinterpretações; isso culminou na produção da política que busca transformar em prática os discursos produzidos em torno da legislação, visto que, para Bernstein (1996), o discurso não se resume a uma mera realização da linguagem, mas um elemento de uma complexa rede de relações sociais e de poder.

É importante analisar os meios pelos quais se constrói uma relação de poder, pois, em cada contexto social, seja com relação à classe, gênero ou religião, surgem diferentes práticas discursivas com muitos significados. Essa particularidade apoia-se na concepção de uso da linguagem e dos discursos abordados nos documentos oficiais no campo da produção de texto para as relações étnico-raciais, uma vez que "[...] quando alguém usa a linguagem o faz de algum lugar localizado na história, na cultura e na instituição, definido nas múltiplas marcas de sua identidade social e à luz de seus projetos políticos, valores e crenças" (BERNSTEIN, 1996, p. 35).

De acordo com Bernstein (1996), o Discurso Pedagógico (DP) inclui três níveis fundamentais: a produção, a recontextualização e a transmissão. Esse discurso é determinado por um conjunto complexo de relações que pressupõe a intervenção de diferentes campos e contextos, desde o macronível - campo de Estado - até o micronível - sala de aula. Assim, ao analisarmos os documentos oficiais que compõem a política curricular do Instituto Federal Baiano, acessamos o macronível desta política, e as entrevistas realizadas com as professoras de Arte, Língua Portuguesa e História nos proporcionaram o acesso ao micronível. Dessa forma, as extensões do discurso Pedagógico Oficial (DPO) estão relacionadas com o que se ensina e com a forma como se ensinam os conhecimentos sobre as relações étnico-raciais nas referidas disciplinas.
No que diz respeito às regras recontextualizadoras, Bernstein (1996) compreende que o discurso pedagógico pode ser definido como as regras para introduzir e relacionar dois discursos e, nesse processo de relação, o discurso da competência instrucional é embutido no discurso regulativo de ordem social. 0 princípio recontextualizador do discurso pedagógico age de forma seletiva, apropriando-se, refocalizando e relacionando outros discursos a partir de sua própria ordem, assim "[...] o discurso pedagógico não pode ser identificado com quaisquer dos discursos que ele recontextualiza" (BERNSTEIN, 1996, p. 259). Ao avaliar a estruturação social do discurso pedagógico e as formas de sua transmissão e aquisição, Bernstein (1996) oferece os conceitos teóricos fundamentais que permitem compreender a constituição, transmissão e aquisição dos discursos pedagógicos que permeiam a prática docente no processo de construção do saber escolar.

Nesse sentido, as políticas curriculares ultrapassam os documentos escritos e se apropriam dos conhecimentos escolares construídos dentro e fora das instituições de ensino por meio das relações de poder, do embate cultural, conflitos escolares que permeiam por uma seleção e recontextualização do prescrito na prática diária das ações pedagógicas. De acordo com Bernstein (1996), as regras de reconhecimento e de realização permitem estabelecer uma relação entre a prática que o/a professor/a desenvolve e os diversos contextos nos quais se insere, assim como admite especificar as relações que se dão no interior do contexto no qual essa prática se desenvolve: na sala de aula.

Com base na questão principal da pesquisa, buscamos compreender a concepção de políticas curriculares, bem como das relações étnico-raciais percebidas pelas professoras participantes deste estudo, a fim de apreender o entrecruzamento entre o discurso oficial e o discurso pedagógico por meio das práticas educativas, do saber escolar como um saber 
que parte do conhecimento científico, mas se diferencia deste pelas suas especificidades, ou seja, pela forma como esse conhecimento é constituído, construído e transformado no contexto escolar e da sala de aula.

Nessa perspectiva, a prática pedagógica das professoras na relação com o saber escolar pode ser compreendida com base nas regras de reconhecimento e de realização e nos princípios recontextualizadores do discurso pedagógico. Assim, ficou evidente que a professora que detém maior conhecimento sobre as questões étnico-raciais, pelas suas vivências ou mesmo estudo, tem oportunidade de recontextualizar de forma distinta das demais professoras que possuem apenas o conhecimento dos marcos oficiais, ou seja, das determinações da legislação vigente.

Assim sendo, é necessário considerar a prática pedagógica docente como uma prática social intercruzada, na qual aquilo que se ensina não é somente o que propõe o currículo prescrito, mas, principalmente, o saber construído ao longo de uma formação, o que proporciona ao princípio recontextualizador atuar num determinado nível da prática, possibilitando que refocalize determinados discursos e crie um discurso pedagógico específico ao contexto no qual se desenvolve, mediante as influências que essa prática recebe dos diversos saberes que se entrecruzam no cotidiano da escola e da sala de aula.

Subsidiamos, também, nossa análise, no ciclo de políticas de Ball e Bowe (1992); este último considera que a maior parte das políticas são inconstantes, produto de acordos, “[...] algo que pode ou não funcionar; elas são retrabalhadas, aperfeiçoadas, ensaiadas, crivadas de nuances e moduladas através de complexos processos de influência, produção e disseminação de textos e, em última análise, recriadas nos contextos da prática" (BALL, 2001, p. 102).

Encontramos, no ciclo de políticas de Ball e Bowe (1992) e nos estudos de Ball (1997, 1998), concepções de política e de método de pesquisa em política curricular que entram em consonância com nossa forma de perceber o campo do currículo como processo de disputas, tanto pela defesa da política curricular como recurso político em construção, quanto pelo modo que sugerem pesquisas em políticas na referida área, como perceptível de traduções e, consequentemente, recriação, superando a ideia de hierarquização das políticas criadas em uma instância estatal, cabendo à escola apenas o papel de implementação ou de resistência (LOPES, 2006).

Para Ball e Bowe (1992), o pesquisador deve fazer uma análise da trajetória de programas e políticas no campo da educação e currículo, desde sua formulação inicial até a sua implementação no contexto da prática e seus efeitos. Nesse sentido, os profissionais que atuam nas escolas não são totalmente excluídos dos processos de formulação ou implementação das políticas. Assim, o foco da análise das políticas deveria incidir sobre a formação de seu próprio discurso e sobre a interpretação - tradução ativa - que os profissionais que atuam no contexto da prática fazem para relacionar os textos da política à prática.

Permite, desse modo, identificar processos de resistência, acomodações, pretextos e conformismo dentro e entre as arenas da prática e o delineamento de conflitos e disparidades entre os discursos nessas arenas (MAINARDES, 2006). Nesta sequência, a abordagem do ciclo de políticas auxilia na análise da produção das políticas curriculares para a educação das relações étnico-raciais, a qual inclui a participação de diversos segmentos da sociedade, ultrapassando a visão estadocêntrica. Para Ball (2001), as políticas curriculares são expressas em textos e discursos e devem ser percebidas como indissociáveis, pois uma está submetida à outra.

Essas políticas, muitas vezes, são vinculadas ao currículo e a documentos, entendidas como criação de propostas curriculares pelo poder público. Contudo, elas não se apresentam somente em termos de documentos oficiais ou textos curriculares, mas, também, as políticas 
de currículo se amplificam para além dos limites do poder público (não são produções instituídas pelo Estado) e oferecem conotações que são forjadas no corpo social da educação. "Ball questiona a ideia de implementação estadocêntrica para a produção de políticas" (CRAVEIRO, 2014, p. 30), uma vez que a política curricular não é manipulada apenas pelo Estado verticalmente, de cima para baixo, perpassa por um processo de pensamento, construção e prática.

Para tanto, a abordagem do ciclo de políticas de Ball e Bowe (1992) possibilita realizar a análise da política curricular para educação das relações étnico-raciais do contexto da influência ao contexto da produção de texto. A análise aqui empreendida parte da compreensão de que as políticas são textos interpretados de maneira complexa em meio a muitas compreensões, negociações, convenções e alianças que refletem a própria historicidade (BALL; BOWE, 1992). Essa abordagem compreende que as fases de formulação e implementação das políticas não são estanques ou lineares. Os processos políticos sofrem reinterpretações por parte dos sujeitos envolvidos na política. Assim, acreditamos que o ciclo de políticas proposto por esses autores permitirá analisar a política curricular para a educação das relações étnico-raciais da prescrição à recontextualização, uma vez que o ciclo de políticas, “[...] permite a análise crítica da trajetória de programas e políticas educacionais, desde sua formulação inicial até a sua implementação no contexto da prática" (MAINARDES, 2006, p. 58).

Nesse estudo, a política é entendida como cíclica, dinâmica e não linear. Para Ball e Bowe (1992), a análise articula os contextos micro e macro, conferindo importância à formação do discurso da política e à interpretação ativa feita por profissionais que atuam no contexto da prática para relacionar os textos da política à prática. Para analisar o ciclo da política, esses autores destacam a dinâmica e a inter-relação entre três contextos: o contexto de influência, o contexto do texto e o contexto da prática. Cada um dos contextos apresenta arenas, lugares e grupos de interesse e cada um deles envolve disputas e embates (MAINARDES, 2007).

0 contexto de influência representa arenas em que os grupos de interesse disseminam discursos políticos e definições das finalidades sociais da educação e do que significa ser educado. Nesse contexto, atuam agentes nacionais e internacionais como partidos políticos, governo, acadêmicos, organismos internacionais e agências multilaterais. 0 contexto do texto toma a forma de textos políticos, comentários formais e informais sobre os textos oficiais, pronunciamentos, dentre outros.

Há uma relação simbiótica com o contexto de influência (MAINARDES, 2007), porém não é tão evidente ou simples. Também é um espaço em que grupos competem para controlar a representação e o propósito da política (OLIVEIRA; DESTRO, 2005). Com efeito, o contexto da prática consiste nas possibilidades e limites materiais e culturais daqueles que exercem a política de currículo nas escolas. Assim, Mainardes (2007) compreende as políticas como produto de um nexo de influências e interdependências que resultam numa interconexão, multiplexidade e hibridização, isto é, a combinação de lógicas globais, distantes e locais (BALL; BOWE, 1992; BALL, 2001).É com esse sentido de política que empreendemos as inflexões sobre a política curricular para as relações étnico-raciais no Brasil.

\section{Educação para as relações étnico-raciais: do contexto da produção ao contexto da prática}

No contexto do Instituto Federal Baiano, as relações étnico-raciais apresentam-se no Plano das Diretrizes Institucionais - PDI, no título Princípios e Diretrizes Orientadoras da Prática Pedagógica (INSTITUTO FEDERAL BAIANO, 2016). 0 texto do documento pondera que a educação dos Institutos Federais se pauta numa educação transdisciplinar, interdiscipli- 
nar, educação para as relações étnico-raciais a fim de transformar a prática pedagógica. Contudo, sabe-se que nenhuma legislação ou diretriz governamental por si só é capaz de produzir transformações, principalmente no campo da produção e transmissão de conhecimentos que por séculos estiveram fora do espaço acadêmico ou nele foram colocados nos textos curriculares de forma marginal e não prioritária. Esta forma de conceber as questões raciais no currículo escolar é "[...] a expressão do equilíbrio de interesses e forças que gravitam sobre o sistema educativo num dado momento, enquanto que através deles se realizam os fins da educação no ensino escolarizado" (SACRISTÁN, 2000, p. 17).

Ao analisar as narrativas das professoras sobre a compreensão de educação para as relações étnico-raciais (SANTOS, 2018), obtivemos respostas que apontam para incipiência da temática no contexto da prática:

As relações étnico-raciais são muito importantes. E depois da legislação tudo ficou mais visível, mais claro. Quando me formei, a lei já tinha sido sancionada, mas a compreensão vai acontecendo aos poucos. (PROFESSORA DE PORTUGUÊS) (SANTOS, 2018, p. 86).

Para mim as relações raciais... [...] a primeira coisa que vem à minha mente quando você fala de 'racial' é a cor da pele, o que é uma ideia inicial normal, mas que é muito mais ampla do que isso, envolve identidade, cultura, as religiões, [...] afrodescendentes. (PROFESSORA DE ARTE) (SANTOS, 2018, p. 86).

As relações étnico-raciais são as relações entre pessoas de várias raças; é muito importante. (PROFESSORA DE HISTÓRIA) (SANTOS, 2018, p. 86).

Observamos, pelas respostas das professoras, as dificuldades em definir educação para as relações étnico-raciais, o que não é difícil compreender visto que, ao longo da pesquisa, percebemos que as discussões sobre a temática nas disciplinas não conseguem ultrapassar o proposto nos manuais curriculares. Dessa forma, Gonçalves (1985) analisa que o preconceito racial e a discriminação se proliferam nas escolas por meio de mecanismos ou fun- cionamento do ritual pedagógico entendido como a materialização da prática pedagógica vivenciada na sala de aula a qual exclui dos currículos escolares a história de luta dos negros na sociedade brasileira.

Nota-se, pela narrativa da Professora de Português, que este conceito está sendo construído e é algo lento. Nesse sentido, o papel do educador é determinante no processo de reapropriação e reinvenção do conhecimento através da análise crítica dos textos, de questionamentos das ilustrações, da comparação do que se lê com o que se vê e da comparação do que se lê nos textos oficiais com o seu cotidiano, suas experiências e sua cultura. A intervenção do/a professor/a imbuído das discussões étnico-raciais pode desconstruir estigmas relacionados e minimizar a discriminação racial do ambiente escolar.

Quando a Professora de Arte diz que a primeira coisa que vem em sua mente quando se fala de educação para as relações étnico-raciais é a cor da pele, observa-se o que nos ensina Gomes (2001) no momento em que fala que a dificuldade apresentada pela maioria da população quanto à identificação racial é ranço da construção histórica da negação, do desprezo e do medo do diferente, visto que ser negro no Brasil possui uma complexidade maior e não se restringe a um dado biológico; é uma postura política.

No Brasil, ser negro é tornar-se negro. 0 conhecimento dessas questões pode nos ajudar a superar o medo e/ou desprezo das diferenças raciais ainda presente na escola e na sociedade. Entender essa complexidade é uma tarefa dos/ as profissionais da educação. É tarefa de uma escola que se quer cidadã e, por isso mesmo, não pode deixar de incluir a questão racial no seu currículo e na sua prática. (GOMES, 2001, p. 89).

É imperioso desmistificar essa ideia da cor da pele como definição de relações étnico-raciais, pois, como afirmam as diretrizes "[...] ser negro no Brasil não se limita às características físicas. Trata-se, também, de uma escolha política. Por isso, o é quem assim se define" (BRASIL, 2004a, p.15). Destarte, para educar a fim de atender à 
diversidade e combater todo tipo de discriminação é preciso compreender que relações étnico -raciais é a convivência de "[...] negros e brancos, no sentido de que venham a relacionar-se com respeito, sendo capazes de corrigir posturas, atitudes e palavras que impliquem desrespeito e discriminação" (BRASIL, 2004a, p. 15).

Como exemplo dessa ideia, apresentamos a fala da Professora de História (SANTOS, 2018, p. 86): “As relações étnico-raciais são as relações entre pessoas de várias raças; é muito importante". Ainda que incipiente, a professora aponta para alguma característica do conceito de educação para as relações étnico-raciais. Para Gomes (2001), as relações étnico-raciais são relações submersas na alteridade e construídas historicamente nos contextos de poder e das hierarquias raciais brasileiras, nos quais a raça opera como forma de classificação social, demarcação de diferenças e interpretação política e identitária. Trata-se, portanto, de relações construídas no processo histórico, social, político, econômico e cultural.

Por tudo isso é que a escola tem papel importante a cumprir nesse debate. É imperioso que os/as professores/as se apropriem do discurso antirracista e compreendam que as diferenças, mais do que dados da natureza, são construções sociais, culturais, políticas e identitárias. Compreender as determinações da legislação vigente - Lei no 10.639 (BRASIL 2003) - permite interferir pedagogicamente na edificação de uma pedagogia da diversidade e garantir o direito à educação e ao conhecimento sobre a história e a cultura africanas e afro-brasileiras. Esse entendimento poderá nos ajudar a ultrapassar opiniões preconceituosas sobre os negros, a África e a diáspora, a denunciar o racismo e a discriminação racial e a implementar ações afirmativas, rompendo com o mito da democracia racial (GOMES, 2011).

\section{Práticas pedagógicas}

Nesta seção, buscamos compreender como as orientações dos documentos são traduzidas e recontextualizadas nas práticas pedagógicas das professoras pesquisadas. Para tanto, utilizamos como categoria analítica as metodologias e a recontextualização. Segundo Mainardes e Marcondes (2009, p. 305):

0 processo de traduzir políticas em práticas é extremamente complexo; é uma alternação entre modalidades. A modalidade primária é textual, pois as políticas são escritas, enquanto que a prática é ação, inclui o fazer coisas. Assim, a pessoa que põe em prática as políticas tem que converter/transformar essas duas modalidades, entre a modalidade da palavra escrita e a da ação, e isto é algo difícil e desafiador de se fazer. E o que isto envolve é um processo de atuação, a efetivação da política na prática e através da prática. É quase como uma peça teatral. Temos as palavras do texto da peça, mas a realidade da peça apenas toma vida quando alguém as representa. E este é um processo de interpretação e criatividade e as políticas são assim.

Os autores abordam o conceito de interpretação e de tradução das políticas realizadas pelos diversos atores no processo de colocá-las em ação. A interpretação trata de uma estratégia de decodificação da política a partir da interação das demandas da escola com as necessidades apresentadas. Para isso, é fundamental a realização da leitura da política com o objetivo de se atribuir um sentido para aquele contexto local e para as histórias dos sujeitos envolvidos. Para Ball, Maguire e Braun (2016), algumas questões são essenciais a essa leitura para a construção de uma metodologia que interprete de forma coerente a política: o que este texto significa para nós? 0 que temos de fazer? Nós temos de fazer tudo?

A tradução trata da tática de efetivação da política, a partir de sua interpretação. Isso significa que a tradução da política é realizada com a finalidade de se criar textos institucionais e da colocação desses textos em ação por meio de conversas, de reuniões, de planos, de eventos, de formas de aprender, bem como de produzir artefatos e emprestar ideias e práticas a outras escolas, adquirir materiais, consultar websites oficiais e receber suporte oferecido por membros das autoridades locais. Segundo 
Ball, Maguire e Braun (2016), essas traduções também dão valor simbólico à política.

A prática pedagógica é entendida, na percepção de Sacristán (2000), como uma ação do professor no espaço de sala de aula. Neste sentido, o/a professor/a assume a função de guia reflexivo; é aquele que orienta as ações em sala de aula e interfere significativamente na construção do conhecimento do/a aluno/a. A prática do/a professor/a completa o ciclo de políticas. Sendo assim, o/a professor/a é o elemento fundamental na concretização do processo ensino-aprendizagem. Este desempenhará o papel de transmissão e recontextualização do currículo, por isso é importante a consciência do seu papel para execução e desenvolvimento de práticas que tornarão o currículo eficaz.

Segundo Bernstein (1996), os discursos pedagógicos produzidos em nível do campo de recontextualização pedagógica são inseridos no nível de transmissão. Eles podem sofrer ainda um processo de recontextualização que depende do contexto específico de cada escola e da prática pedagógica de cada professor. Desta forma, o discurso reproduzido pelos/as professores/as em salas de aula é influenciado pelas relações que caracterizam os contextos específicos da sua trajetória. A transmissão de um conhecimento pode ser influenciada pelas relações que se estabelecem entre os contextos da escola e da família e comunidade.

Quando perguntamos às professoras se após o conhecimento das políticas curriculares para a educação das relações étnico-raciais houve alguma ação por parte delas, obtivemos a seguinte resposta de uma das docentes:

Não há ações direcionadas para trabalhar as propostas previstas na legislação; as atividades partem do bom senso do docente e do seu conhecimento construído por outros meios de informação. Não há um estudo organizado que direcione para ações pontuais a respeito do assunto tratado na Lei 10.639. (PROFESSORA DE PORTUGUÊS) (SANTOS, 2018, p. 90).

Fica evidente na fala da entrevistada que as políticas curriculares para educação das relações étnico-raciais não conseguiram mudar suas práticas curriculares. A professora reconhece, portanto, a necessidade de um estudo organizado que direcione para ações pontuais a respeito das relações étnico-raciais. Por este ângulo, Bernstein (1996) utiliza o conceito de dispositivo pedagógico, que consiste num conjunto de regras que regula internamente a comunicação pedagógica e incide sobre uma série de significados passíveis de serem transmitidos pela escola. Para realizar a seleção de quais significados serão trazidos para o currículo escolar - e da forma pela qual eles serão tratados -, as regras do dispositivo pedagógico contam com relativa estabilidade e expressam as posições dominantes na arena de disputa pela hegemonia em determinado grupo social. Assim, o dispositivo pedagógico não é ideologicamente neutro e a relativa estabilidade de suas regras se deve à ligação que mantém com a distribuição do poder e das formas de manutenção da ordem social.

O dispositivo pedagógico consiste no meio pelo qual se relaciona poder, conhecimento e consciência, ou seja, é uma atividade moral fundamental e atua por meio de três conjuntos de regras relacionadas entre si: as regras distributivas, recontextualizadoras e de avaliação. As regras distributivas possuem a função de regular as relações entre o poder, os grupos sociais, as formas de consciência e a prática. As regras recontextualizadoras regulam a constituição do discurso pedagógico específico. E as regras de avaliação são constituídas na prática pedagógica (BERNSTEIN, 1996). Posto isso, percebe-se a contribuição de Bernstein (1996) na formulação da teoria do dispositivo pedagógico para entender o processo pelo qual um campo específico de conhecimento é transformado em um sistema de conhecimento escolar, curricular, disciplinar, enfim, como ele é praticado e recontextualizado.

Sendo assim, a fala da Professora de Português nos permite compreender que o ensino da História e cultura afro-brasileira, como proposto pelas políticas curriculares vigentes, 
constitui um caminho ainda incipiente e que necessita ser ampliado no IF Baiano campus Guanambi. Contudo, percebemos que essa tarefa não será muito fácil, visto que desenhar um campo de atuação para o ensino de História e cultura afro, além dos desafios políticos estruturais e burocráticos, exige a formulação de objetivos das várias perspectivas teóricas. Os conteúdos dessa disciplina e a metodologia de ensino da educação para as relações étnico-raciais "[...] recebem influências de vários campos e expressam variadas correntes teóricas, nas quais se admite a existência de diversas interpretações e explicações, que, por sua vez, não são vazias de sentido político" (SOUZA, 2015, p. 103).

Desse modo, concordamos com a ideia de Bernstein (1996) em que os agentes controlam a produção dos discursos ou textos; não somente pautam as questões mais relevantes, mas, sobretudo, controlam a vida social na medida em que as "verdades consensuais" estão sob seu domínio. Da forma como está posta a obrigatoriedade do ensino de História e Cultura afro-brasileira nos documentos curriculares, a sua recontextualização fica comprometida, visto que o ensino das questões étnico-raciais acontece quando o/a professor/a decide que é importante, uma vez que a não disciplinarização tende a confirmar uma prática de exclusão da temática, deixando-a solta no universo escolar. Isso se confirma na fala de mais uma das professoras entrevistadas: "[...] não tem como trabalhar com Arte e Arte do Brasil sem pensar na contribuição da África e dos africanos, [...] então, assim, é muito [...] Ficaria muito superficial, não tem como [...] porque é a base da cultura brasileira" (PROFESSORA DE ARTE) (SANTOS, 2018, p. 91).

De acordo com Professora de Arte, não tem como trabalhar com a disciplina sem pensar na contribuição da África para a nossa cultura, enquanto a Professora de História afirma que traz a questão da escravidão para que os alunos compreendam as políticas de reparação: "Sim, eu trabalho com a questão da escravidão [...] é um trabalho de aceitação, [...] eu peguei o fim da escravidão então isso fortalece mais a compreensão que eu trago para os alunos que é [...] o reconhecimento de políticas diferenciadas para o negro" (PROFESSORA DE HISTÓRIA) (SANTOS, 2018, p. 91).

Percebemos, por meio dessas narrativas, que os interesses e motivações de se ensinar a História e Cultura Afro-brasileira no Instituto estão inseridos no contexto de formação das professoras. A educação para as relações étnico-raciais proposta nas diretrizes acontece quando a Professora de História afirma que trabalhar com a história da escravidão é uma forma de também educar para a aceitação e reconhecimento das políticas de reparação. No entanto observamos, também, por meio das narrativas das professoras, que não existe uma normatização para o ensino de História e Cultura Afro-brasileira, pois este acontece de forma não padronizada, sem a rigidez necessária para criar uma identidade legitimadora e transformadora. Entender e educar para as relações étnico-raciais deve proporcionar uma classificação e um enquadramento fortes (BERNSTEIN, 1996) para que a História e a Cultura Afro-brasileira sejam facilmente identificadas e legitimadas.

\section{A relação étnico-racial e 0 nexo com as disciplinas de língua portuguesa, arte e história}

O Parecer CNE/CP no 3 (BRASIL, 2004b) determina a inclusão de conteúdos da História e da Cultura Afro-brasileira nos currículos escolares. No entanto, isso não significa que se mude o foco de uma história eurocêntrica para uma história centrada na África. Entendemos que o objetivo da política é que sejam abordados conteúdos que levem à percepção da diversidade cultural, social e econômica brasileira. As diretrizes (BRASIL, 2004a) deixam claro, em seu texto, que cumprir a lei não é 
responsabilidade apenas do professor em sala de aula, mas de todos os envolvidos no processo de educação brasileira; a meta é o pleno desenvolvimento do ser humano e o preparo para o exercício da cidadania.

Nesse sentido, as diretrizes determinam bem mais do que a adição de novos conteúdos; pretendem que se repensem ações que contemplem as questões étnico-raciais, sociais e pedagógicas que possibilitem o processo de aprendizagem baseado na diferença, na diversidade e, principalmente, no entendimento das contribuições dos povos afro-brasileiros em todos os segmentos nacionais. Além disso, o discurso sugere considerar a sociedade brasileira como um todo, composto por diversas culturas e etnias.

Quando questionada sobre a relação da sua disciplina com o que propõe as diretrizes curriculares nacionais para educação das relações étnico-raciais (DCNERER), a Professora de Português (SANTOS, 2018, p. 93) respondeu:

\begin{abstract}
A língua e a linguagem permitem ao indivíduo comunicar e conhecer como viveu o homem de diferentes épocas. Desse modo, a disciplina de Língua Portuguesa pode contribuir para o entendimento e avanço nas interpretações acerca da temática contrastada por diferentes períodos históricos. Além disso, na prática, o letramento dos alunos em sala de aula lhes permite sair da invisibilidade inerente à organização curricular brasileira e assumirem-se como sujeitos sociais. Logo, o letramento é uma forma eficiente de dar voz a indivíduos marcados pela exclusão não só linguística, mas culturalmente marcados por relações étnicas que negligenciam e suprimem as minorias das práticas socioculturais. 0 letramento é, portanto, um importante mecanismo para vencer as desigualdades sociais e afirmar as identidades afro-brasileiras.
\end{abstract}

Aqui, a professora trata do papel do letramento para a inclusão do sujeito na sociedade e na construção de um conhecimento histórico crítico a respeito da realidade que, de certa forma, não está fora dos propósitos das políticas curriculares para as relações raciais. Contudo, demonstra o seu limite no que se refere à amplitude que abarca a temática, o que significa que "[...] tais políticas têm como meta o direito dos negros se reconhecerem na cultura nacional, expressarem visões de mundo próprias, manifestarem com autonomia, individual e coletiva, seus pensamentos" (BRASIL, 2004a, p. 10). Além disso, é necessário reconhecer a importância dos/as negros/as para a construção social, cultural e econômica do país, visto que o "[...] reconhecimento requer a adoção de políticas educacionais e de estratégias pedagógicas de valorização da diversidade, a fim de superar a desigualdade étnico-racial presente na educação escolar brasileira, nos diferentes níveis de ensino" (BRASIL, 2004a, p. 12).

Em outra direção, as professoras de Arte e História falam das contribuições de suas disciplinas em suas práticas pedagógicas a fim de desmistificar o preconceito racial. A docente de Arte assim relata: "As discussões, [...] sobre preconceito, sobre as contribuições do negro, sobre a constituição da identidade baiana, não só brasileira, mas especialmente baiana, são contempladas em minha disciplina; eu falo da contribuição da música afro para a nossa cultura" (PROFESSORA DE ARTE) (SANTOS, 2018, p. 93).

A Professora de História (SANTOS, 2018, p. 93) diz que questiona com os/as alunos/ as: "Você é contra ou a favor de cotas raciais? Por que é a favor ou contra?" Ela complementa dizendo: "É essencial eles entenderem que se a gente trabalha hoje com as políticas raciais [...] é consequência da falta de assistência pública que houve no início da abolição". As falas das professoras contemplam as propostas da legislação vigente, visto que no âmbito das políticas de promoção da igualdade racial, a Lei no 10.639 (BRASIL, 2003) busca desconstruir estereótipos a respeito do continente africano e dos afro-brasileiros, exigindo o reconhecimento e a valorização de culturas e identidades historicamente discriminadas e invisibilizadas. Nesse sentido, a prática pedagógica das professoras entrevistadas pode configurar-se como possibilidade na perspectiva da superação desses mecanismos ideológicos que dão 
sustentação às desigualdades raciais e sociais no Brasil.

Nesse contexto, a recontextualização que propõem os documentos oficiais na prática pedagógica poderá contribuir para a superação de anos de desigualdades e injustiças que se estabeleceram no sistema educacional brasileiro. Quanto a isso, as DCNERER ressaltam que:

Políticas de representações voltadas para a educação dos negros devem oferecer garantias a essa população de ingresso, permanência e sucesso na educação escolar, de valorização do patrimônio histórico-cultural afro-brasileiro de aquisição das competências e dos conhecimentos [...] (BRASIL, 2004a, p. 11).

O discurso recontextualizador pedagógico dos documentos oficiais, para além de levantar uma série de princípios a respeito da questão racial e educação, apresenta um conjunto de indicações de conteúdo a ser abrangido pelo currículo nas diferentes áreas do conhecimento.

Bernstein (1996) define o processo de mover um discurso de uma posição para outra como recontextualização pedagógica. Esse autor reconhece que "[...] quando um discurso é movido por recontextualização do seu contexto original para o contexto pedagógico, o discurso original é abstraído da sua base social, posição e relações de poder" (BERNSTEIN, 1996, p. 38). Dessa forma, temos como exemplos as disciplinas escolares como modelo de discursos recontextualizados, uma vez que elas foram direcionadas do campo acadêmico e reposicionadas para servir a determinados propósitos no contexto escolar.

Ao analisarmos os discursos das professoras percebemos, em suas narrativas, o que cada uma seleciona a partir do que considera importante para contemplar a proposta curricular; fazem isso quando definem o que deve ou não ser transmitido. Assim, de acordo com o conhecimento que se tem sobre as relações étnico-raciais, decidem quais as atividades necessitam ser realizadas. Dessa forma, fica visível que o discurso proveniente dos campos recontextualizadores, seja oficial ou pedagógi- co, muitas vezes funciona como um discurso regulativo, na medida em que o professor e/ ou ator recontextualizador é quem define o que deve ser dito e como deve ser dito. Com base na teoria de Bernstein (1996), ao fazer essa adequação, estamos recontextualizando e dando significados ao texto produzido. Nesse sentido, o discurso pedagógico não é neutro, pois "[...] sempre que o discurso se move, há espaço para a ideologia atuar" (BALL, 2001, p. 102).

Sendo assim, Bernstein (1996) afirma que o modo como a sociedade seleciona, classifica, distribui, transmite e avalia o conhecimento reflete a distribuição de poder e os princípios de controle social. Assim, as transformações na reorganização, na transmissão e na avaliação do conhecimento educacional devem ser observadas, visto que mudanças nos códigos educacionais traduzem alterações nas estruturas de poder e de controle que, por sua vez, afetarão a forma das relações sociais, assim como a forma com que a prática pedagógica é moldada na estrutura mental dos estudantes.

\section{Considerações finais}

Esta pesquisa abriu passagem para a compreensão de determinados aspectos das políticas curriculares para as relações étnico-raciais e a recontextualização nas práticas pedagógicas. Percebemos que abordar as relações étnico-raciais nos espaços escolares é imergir em constatações das situações de invisibilidade, silenciamento, negação e disputa de poder, ações praticadas naturalmente no cotidiano educacional. A fundamentação teórica a partir do campo das teorias críticas e pós-críticas de currículo nos trouxe a compreensão dos interesses que envolvem a construção das políticas curriculares no Brasil para relações étnico-raciais, bem como possibilitou um olhar mais crítico nos atuais modelos curriculares, observando o que eles trazem e em que precisam ser restabelecidos, com o objetivo de promover mudanças. 0 currículo, considerado 
um espaço de poder, um meio pelo qual é reproduzida e mantida uma ideologia dominante, pode também ser um espaço de construção, de libertação e de autonomia.

Por outro lado, as contribuições do ciclo de política de Ball (1994a) e da teoria da recontextualização de Bernstein (1996) possibilitaram a compreensão de como as políticas são construídas e, principalmente, a forma como transitam no espaço escolar. Neste sentido, buscamos conhecer como as concepções de política curricular, currículo e educação para as relações étnico-raciais, disponíveis nos documentos e discursos das professoras, agentes desta pesquisa, são interpretadas e recontextualizadas no IF Baiano - campus Guanambi. Percebemos, no diálogo entre as normativas legais e as narrativas das entrevistadas, que grupos de atores diferentes interpretam e atuam a política em contextos específicos ou mesmo iguais de formas diferentes.

Apreendemos também que as políticas estão em permanente movimento através do tempo e do espaço; compreendemos que uma política, além de processo e consequência, é texto e também discurso. E essas duas conceituações, texto e discurso, são complementares e estão implícitas uma na outra (BALL, 1994b).

A política como texto refere-se aos documentos oficiais; no caso desta pesquisa, à Lei $\mathrm{n}^{\mathbf{0}}$ 10.639 (BRASIL, 2003), às DCNERER (BRASIL, 2004a), a o PDI (INSTITUTO FEDERAL BAIANO, 2014), ao PPP (INSTITUTO FEDERAL BAIANO, 2016), entendidos como produtos inacabados de esforços coletivos, em múltiplos níveis de interpretação e tradução. É uma representação, codificada de maneira complexa, que permite uma multiplicidade de leituras em razão da pluralidade de leitores. Isso significa admitir as políticas como mediações que são codificadas de formas complexas a partir de embates, acordos e interpretações e reinterpretações por parte das autoridades públicas, e decodificadas, também de maneiras complexas, pela interpretação por parte dos atores envolvidos, atribuindo significados em razão de suas his- tórias, experiências e possibilidades (BALL, 1994a).

Além disso, percebemos a política como discurso por meio das narrativas das professoras. Esta forma de entender a política se estabelece pelas disputas de poder, pelo controle de bens (recursos) e de discursos, em termos de vantagens e legitimidade sociais. Enfatiza os limites impostos pelo próprio discurso que não é falado, mas nos fala. Embora haja variedade de discursos, alguns são dominantes em relação a outros, construindo e permitindo as subjetividades, as vozes, o conhecimento e as relações de poder. Operam no que pode ser dito e pensado, mas também sobre quem pode falar, quando, onde e com que autoridade. Assim, edificam certas possibilidades de pensamentos, conceitos e excluem outros, fazendo com que as lutas sobre a interpretação e aprovação de políticas ocorram e se ajustem dentro de uma estrutura discursiva movente que articula e restringe as possibilidades e probabilidades de interpretação e aprovação (BALL, 1994b).

Dessa forma, concordamos com Ball, Maguire e Braun (2016) quando afirmam que os agentes interpretam e traduzem as políticas no processo de colocá-las em ação. A interpretação trata de uma estratégia de decodificação da política, a partir da interação das demandas da escola com as necessidades políticas apresentadas. Isso significa que a leitura da política é realizada com a finalidade de se atribuir um sentido para aquele contexto local e para as histórias dos sujeitos envolvidos. A tradução trata da tática de efetivação da política, a partir de sua interpretação.

Compreendemos, por meio das análises, que existe um elo de influências entre os campos recontextualizadores oficial e pedagógico, visto que todas as agentes desta pesquisa demonstram a fragilidade dos conhecimentos sobre as políticas curriculares para as relações étnico-raciais. Constatamos um nascedouro de conflitos e resistência entre esses dois campos recontextualizadores, pois o saber que existe às determinações legais não signi- 
ficou ter conhecimento de como trabalhar as questões propostas pela legislação na prática pedagógica. Isso leva os sujeitos a se verem como impossibilitados de reproduzir o código de transmissão desejado, uma vez que todo discurso é um discurso recontextualizado e é, ideologicamente, reposicionado e transformado no campo original de sua produção para sua reprodução, sofrendo mudanças do discurso pedagógico (BERNSTEIN, 1996).

Ficou perceptível que as docentes ainda encontram dificuldades no trabalho de articulação entre as questões étnico-raciais e as disciplinas que ministram aulas. Percebemos que as resistências advêm por não terem um referencial, uma direção para iniciar o trabalho com a cultura afro-brasileira, visto que, em sua maioria, as professoras não tiveram, em suas graduações, contato com disciplinas específicas sobre a História da África. Assim, com base nos estudos realizados, nas análises dos documentos oficiais - federal e institucional -, compreendemos que, para além do aporte

\section{REFERÊNCIAS}

BALL, Stephen. Educational reform: a critical and post-structural approach. Buckingham: Open University Press, 1994a.

Some reflections on policy theory: a brief response to Hatcher and Troyna. Journal of Education Policy, v. 9, n. 2, p. 171-182, 1994b.

Educational reform: a critical and poststructural approach. Buckingham: Open University Press, 1997.

Cidadania global, consumo e política educacional. In: SILVA, L. H. (Org.). A escola cidadã no contexto da globalização. Petrópolis, RJ: Vozes, 1998. p. 121-137.

Diretrizes políticas globais e relações políticas locais em educação. Currículo sem Fronteiras, v. 1, n. 2, p. 99-116, jul./dez. 2001. Disponível em: <http://www.curriculosemfronteiras.org/ vol1iss2articles/ball.pdf>. Acesso em: 20 out. 2016.

BALL, Stephen; BOWE, Richard. The policy processes and the processes of policy. In: BOWE, R.; BALL, S.; GOLD, A (Org.). Reforming education \& legal, é no cotidiano das instituições educacionais, compostas por sujeitos, que as ações e as políticas serão ou não recontextualizadas, com maior ou menor grau de importância.

As considerações das entrevistas nos levam ao reconhecimento de que muitos desafios precisam ser enfrentados para que, verdadeiramente, aquilo que se propõe à legislação vigente seja assimilado, interpretado e recontextualizado na prática pedagógica das professoras de Arte, Língua Portuguesa e História do IF Baiano - campus Guanambi. Finalizamos este trabalho com a certeza de que apesar de quase 15 anos da publicação da Lei no 10.639 (BRASIL, 2003), a política curricular para relações étnico-raciais no contexto nacional e no IF Baiano - campus Guanambi carece de ampliação nas discussões no que se refere a formação dos professores para a temática, para assim construir caminhos que assegurem aos agentes sociais desse estabelecimento a integridade de sua dignidade, o respeito e o reconhecimento das diferenças.

changing school: case studies in policy sociology. Londres: Routlegde, 1992. p. 6-23.

BALL, Stephen; MAGUIRE, Meg; BRAUN, Annette. Como as escolas fazem as políticas: atuação em escolas secundárias. Tradução de Janete Bridon. Ponta Grossa, PR: UEPG, 2016.

BERNSTEIN, Basil. A estruturação do discurso pedagógico: classe, códigos e controle. Traduçao Tomaz Tadeu da Silva e Luis Fernando Gonçalves Pereira. Petrópolis, RJ: Vozes, 1996. v. IV.

BRASIL. Diretrizes Curriculares Nacionais para a Educação das Relações Étnico-Racial e para o Ensino de História e Cultura Afro-Brasileira e Africana. Brasília, DF: MEC/ Secretaria Especial de Políticas de Promoção de Igualdade Racial, 2004a.

Parecer CNE/CP no 3, de 10 de março de 2004. Diretrizes Curriculares Nacionais para a Educação das Relações Étnico-Raciais e para o Ensino de História e Cultura Afro-Brasileira e Africana. Brasília, DF, 2004b.

. Lei no 10.639, de 09 de janeiro de 2003. 
Altera a Lei no 9.394, de 20 de dezembro de 1996, que estabelece as diretrizes e bases da educação nacional, para incluir no currículo oficial da Rede de Ensino a obrigatoriedade da temática "História e Cultura Afro-Brasileira", e dá outras providências. Diário Oficial da União, Poder Executivo, Brasília, DF, 10 jan. 2003.

Presidência da República. Casa Civil. Lei no 11.645, de 10 de março de 2008. Altera a Lei no 9.394, de 20 de dezembro de 1996, modificada pela Lei no 10.639, de 9 de janeiro de 2003, que estabelece as diretrizes e bases da educação nacional, para incluir no currículo oficial da rede de ensino a obrigatoriedade da temática "História e Cultura Afro-Brasileira e Indígena". Brasília, DF, 2008. Disponível em:<http://www.planalto.gov.br/ ccivil_03/_ato2007-2010/2008/lei/l11645.htm>. Acesso em: 20 out. 2016.

CRAVEIRO, Clarissa Bastos. Políticas Curriculares para formação de professores: processos de identificação docente (1995-2010). 2014. 174 f. Tese (Doutorado em Educação) - Centro de Educação e Humanidades, Faculdade de Educação da Universidade do Estado do Rio de Janeiro (UERJ), Rio de Janeiro, 2014.

GOMES, Nilma Lino. Educação cidadã, etnia e raça: o trato pedagógico da diversidade. In: CAVALLEIRO, Eliane. Racismo e anti-racismo na educação repensando nossa escola. São Paulo: Summus, 2001. p.83-95.

Educação, relações étnico-raciais e a Lei 10.639/03. 2011. Disponível em: <http://antigo. acordacultura.org.br/artigo-25-08-2011>. Acesso em: 20 set. 2017.

GONÇALVES, Luiz Alberto Oliveira. 0 silêncio: um ritual pedagógico a favor da discriminação racial: um estudo acerca da discriminação racial como fator de seletividade na escola pública de primeiro grau: $1^{\circ}$ a $4^{\circ}$ o série. 1985.250 f. Dissertação (Mestrado em Educação) - Programa de PósGraduação em Educação da Universidade Federal de Minas Gerais (UFMG), Belo Horizonte, 1985.

INSTITUTO FEDERAL DE EDUCAÇÃO, CIÊNCIA E TECNOLOGIA BAIANO. Plano de Desenvolvimento Institucional 2015-2019: identidade e gestão para a construção da excelência! Salvador, 2014.

Projeto Político Pedagógico: a construção coletiva da identidade do campus Guanambi.
2016. Disponível em: <http://www.ifbaiano. edu.br/unidades/guanambi/files/2016/05/ PPP-Campus-Guanambi.pdf>. Acesso em: $20 \mathrm{dez}$. 2016.

LOPES, Alice Casimiro. Discursos nas políticas de currículo. Currículo sem Fronteiras, Porto Alegre, v. 6, n. 2, p. 33-52, jul./dez. 2006. Disponível em: <http://www.curriculosemfronteiras.org/ vol6iss2articles/lopes.pdf>. Acesso em: 20 set. 2017.

MAINARDES, Jefferson. Abordagem do ciclo de políticas: uma contribuição para a análise de políticas educacionais. Educação \& Sociedade, v. 27, n. 94, p. 47-69, jan./abr. 2006. Disponível em: <http://www.scielo.br>. Acesso em: 03 dez. 2016.

Reinterpretando os ciclos de aprendizagem. São Paulo: Cortez, 2007.

MAINARDES, J.; MARCONDES, M. I. Entrevista com Stephen J. Ball: um diálogo sobre justiça social, pesquisa e política educacional. Educação \& Sociedade, Campinas, SP, v. 30, n. 106, p. 303-318, jan./abr. 2009.

OLIVEIRA, Ozerina Victor de; DESTRO, Denise de Oliveira. Política curricular como política cultural: uma abordagem metodológica de pesquisa. Revista Brasileira de Educação, Rio de Janeiro, n. 28, p. 140-150, 2005.

SACRISTÁN, José Gimeno. 0 currículo: uma reflexão sobre a prática. 3. ed. Porto Alegre: Artmed, 2000.

SANTOS, Etelvina de Queiroz. Práticas das políticas curriculares sobre as relações étnico -raciais no Instituto Federal Baiano - Campus Guanambi. 2018. 119 f. Dissertação (Mestrado em Educação) - Universidade Estadual do Sudoeste da Bahia (UESB), Vitória da Conquista, BA, 2018.

SOUZA, Janyne Barbosa de. Entre o discurso oficial e o discurso pedagógico: desafios e caminhos construídos no contexto da rede municipal de ensino de Jequié - Bahia no processo de implantação da Lei 10.639/03. 2015. 146 f. Dissertação (Mestrado em Educação) - Programa de Pós-Graduação em Educação da Universidade Estadual do Sudoeste da Bahia (PPGEd/UESB), Vitória da Conquista, BA, 2015.

Recebido em: 01/05/2018 Aprovado em: 10/01/2019 